\title{
Correction of a Severely Rotated Mandibular Canine in an Adult Patient Using Invisalign: A Case Report
}

\author{
Karina Andrea Pando ${ }^{1 *}$, Edison Román Aguilar ${ }^{1}$, Manuel Estuardo \\ Bravo $^{1}$ \\ ${ }^{1}$ University of Cuenca, Cuenca, Ecuador \\ ${ }^{*}$ Corresponding author: Karina Andrea Pando: k.yandrea@hotmail.com
}

\section{OPEN ACCESS}

Citation: Pando K.A., Aguilar E.R., Bravo M.E. (2018) Correction of a Severely Rotated Mandibular Canine in an Adult Patient Using Invisalign System: A Case

Report.Open Science Journal 3(2)

Received: $30^{\text {th }}$ January 2018

Accepted: $15^{\text {th }}$ March 2018

Published: $8^{\text {th }}$ April 2018

Copyright:@ 2018 This is an open access article under the terms of the Creative Commons

Attribution License, which permits unrestricted use, distribution, and reproduction in any medium, provided the original author and source are credited.

Funding: The author(s) received no specific funding for this work

Competing Interests: The author have declared that no competing interests exists.

\section{Abstract:}

Introduction: The Invisalign system has been used in the orthodontic treatment of numerous types of malocclusions. However some clinicians have reported difficulty incorrecting rotations particularly in canines and premolars using the Invisalign appliance system. This case report describes the orthodontic treatment of an adult patient with severe canine rotation (more than $45^{\circ}$ ) and crowding on upper and lower tooth.

Methods: The clinical examination included extra-oral and intra-oral photographs, panoramic radiographic, lateral cephalometric, stone casts, and upper and lower arch analysis obtained from ClinCheck 3.0.The treatment planning was resolved the crowding in both upper and lower arches and the severe rotation of 33 tooth $\left(46^{\circ}\right)$ using Invisalign system as well as the canine and molar relationship, dental verticalization, adequate over jet, overbite and dental midline using the same system. The duration of the treatment was approximately eight months.

Results: In Post-treatment extra oral photographs, no significant changes were observed at the end of the treatment. Intraoral photographs showed an important and notable improved aesthetics. The canine relationship improved slightly and molar Class Irelationship was maintained. An increase in transverse diameter was observed at the level of first premolars, second premolars and first molars. The overbite was improved. The crowding and the severe canine rotation were corrected. No obvious root resorption was radiographically evident and slight cephalometric changes. 
Conclusion: The treatment with the Invisalign system resolved the complaint of our patient so this system could be considered as an option that offered good results in the treatment of upper and lower crowding of arches involving severe canine rotation.

Keywords: Severe rotation, Canine, Invisalign system.

\section{Introduction}

In recent years, orthodontics treatments have increased their popularity between adults patients being aesthetics [1] and comfort techniques [2] who preferred them. In this context, the aligners have become one of the most growing orthodontic treatment modalities [3]. The Invisalign system (Align Technology) introduced in 1999 has been used as an aesthetic and comfort of the removable clear aligners in comparison with the traditional appliances [4].

Previous studies showed that the Invisalign system is effective in the treatment of "mild to moderate tooth crowding and some cases of severe crowding involving extractions" [5]. The patients that used this system have worn the aligners approximately 22 hours per day except for meals, drinks and dental hygiene [6]. Each aligner is ideally worn for 15 days, moving the teeth at a maximum rate of $0.33 \mathrm{~mm}$ and 2 degrees of rotation per aligner [7].

However, certain limitations have been outlined respect to the aligners and certain tooth movements as extrusion, rotation, bodily movement, and torque [8]. In this context, many clinicians have reported difficulties of correcting rotations particularly in canines and premolars [9].

Severe canine rotation more than $15^{\circ}$ (clinically discernable amount of malrotation) is an orthodontic movement reported to be difficult to achieve and control with the Invisalign system [10]. When rotations are greater than $15^{\circ}$, the accuracy of the canine is significantly reduced [11].

This case report shows the use of the Invisalign system in the treatment of an adult patient with severe canine rotation (more than $45^{\circ}$ ) and crowding on upper and lower tooth.

\section{Case report}

A female patient aged 33 years went to the orthodontic clinic at Cuenca University, Ecuador; the patient's main complaint was "My upper and lower teeth are crocked". An informed consent was obtained from the patient who underwent examination and it was recorded. The clinical examination revealed that the patient presented severe rotation of lower canine (more than $45^{\circ}$ ) and crowding on upper and lower arches. The clinical examination included extra-oral and intra-oral photographs, panoramic radiographic, lateral cephalometric, stone casts, and upper and lower arch analysis obtained from ClinCheck 3.0.

The extra oral examination revealed mesocephalic head, proportional facial thirds, straight anterior profile (Fig1). 

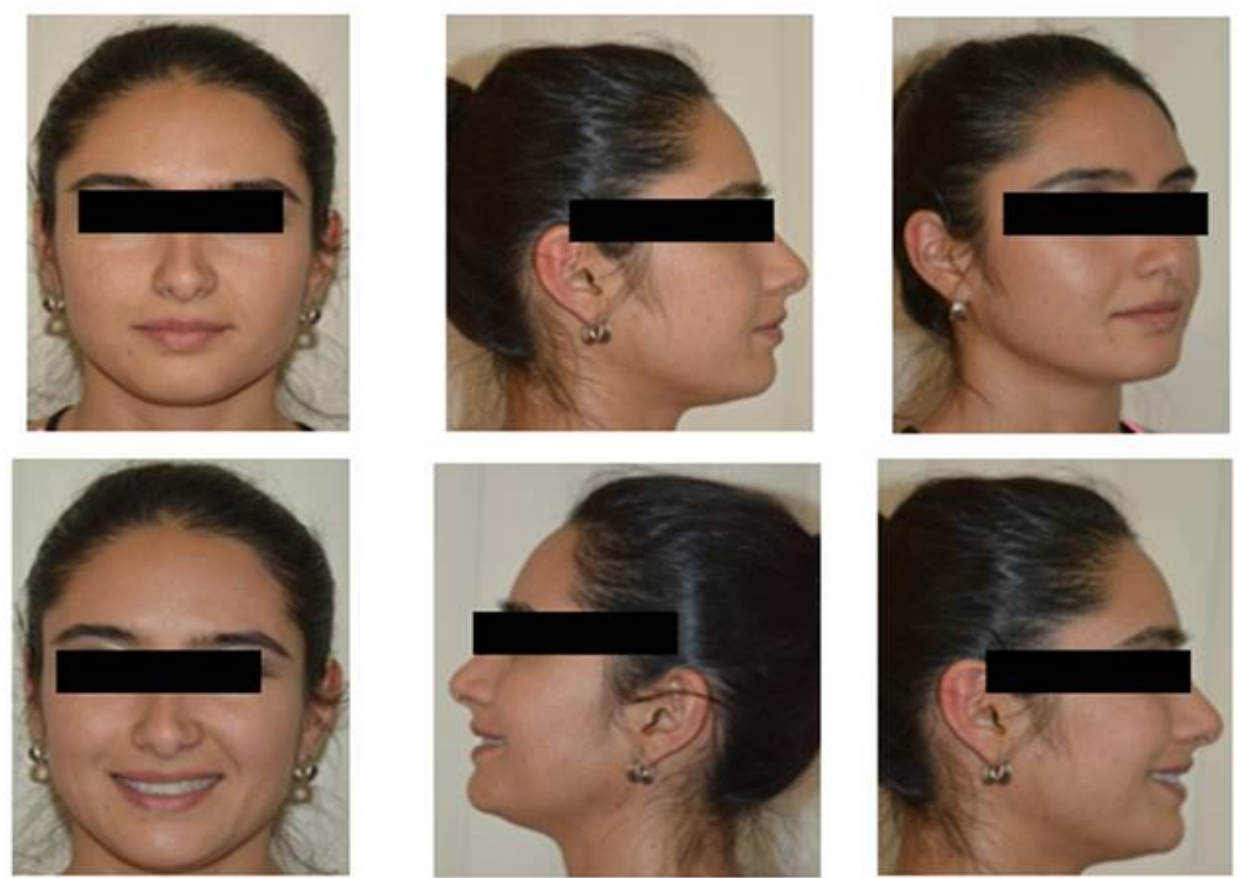

Figure 1. Initial extraoral photographs

Intraoral clinical examination revealed a bilateral Class Imolar relationship, canine distoclusion of $1 / 4$ unit bilateral, horizontal overjet of $3.5 \mathrm{~mm}$ and vertical overbite of $3.5 \mathrm{~mm}$; crowding in both upper and lower arches. Deviated dental middle line and severe rotation of lower canine (33 rotated $46^{\circ}$ ) (Fig 2).
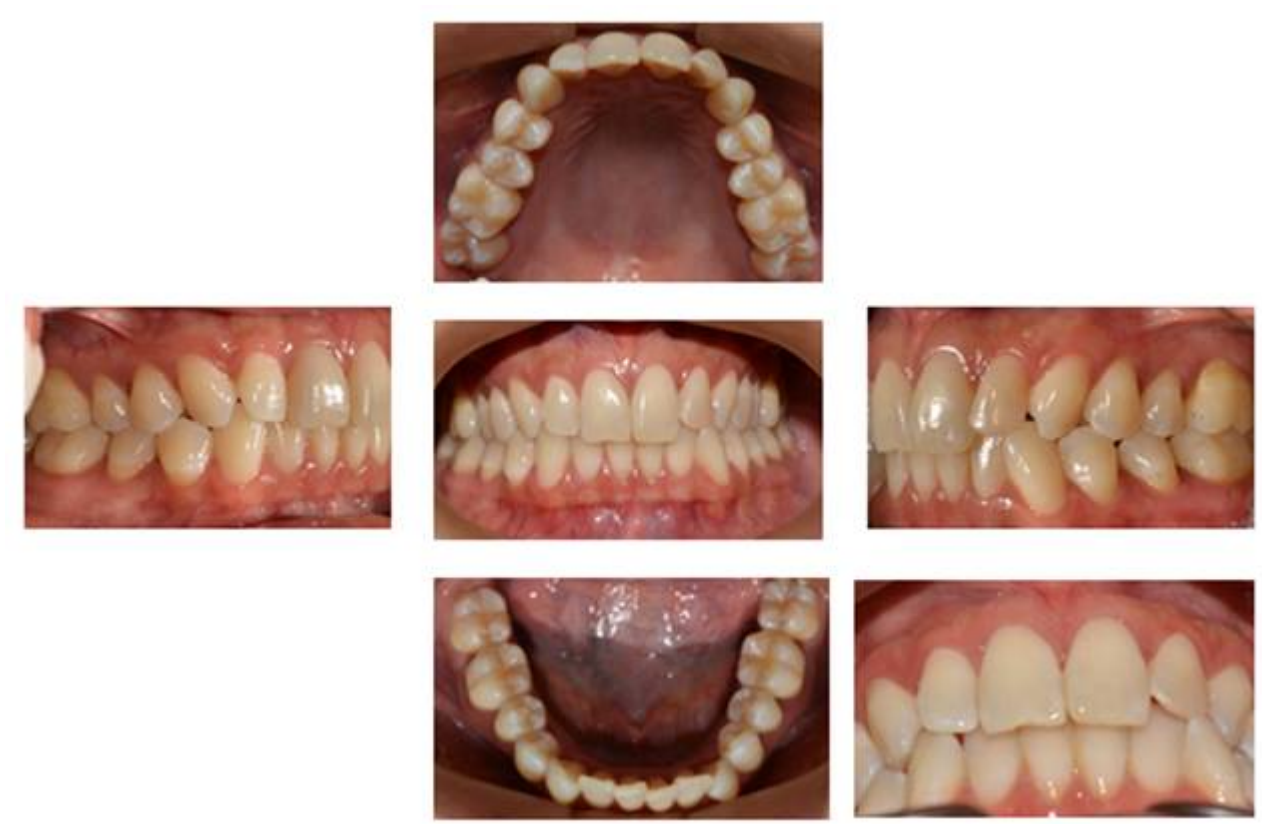

Figure 2. Initial intraoral photographs

The analysis of dental casts showed a dental discrepancy of -3mm for the lower arch and $-2 \mathrm{~mm}$ for the upper arch (Fig 3). 

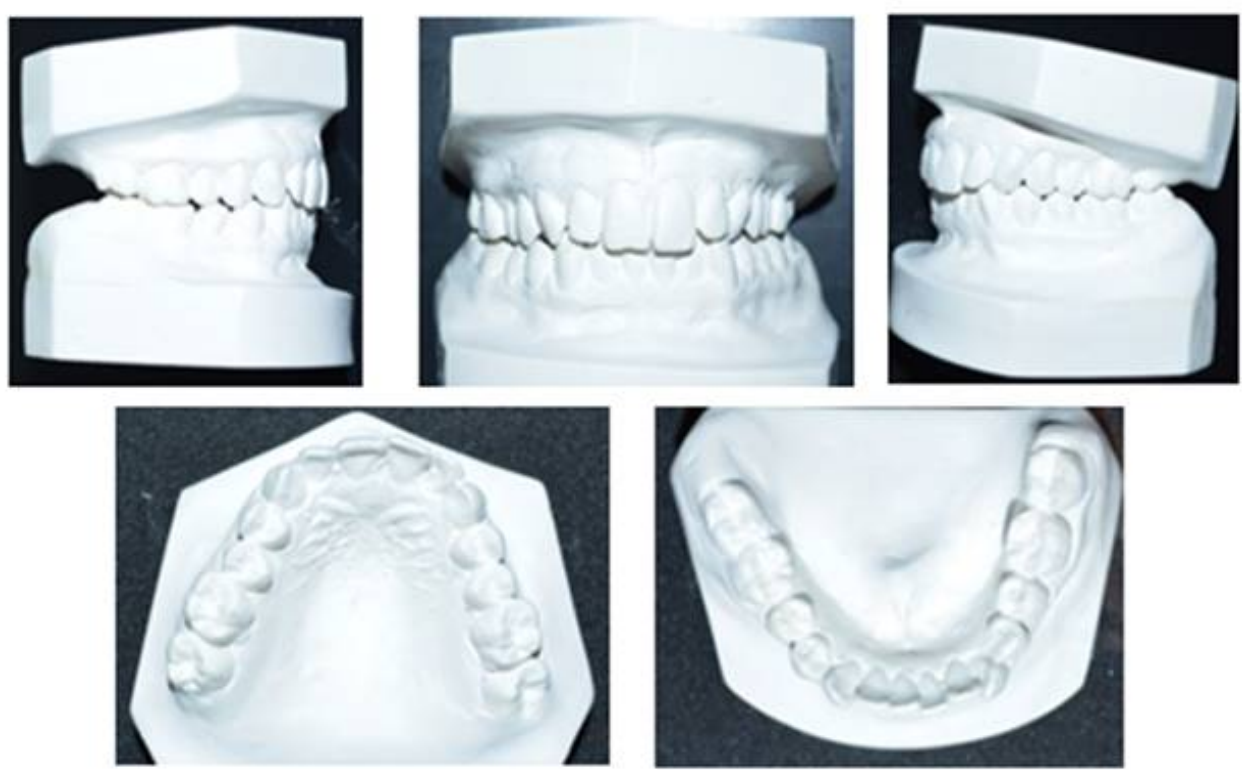

Figure 3. Initial dental cast

The transversal analysis was measured starting at first premolars, second premolars and first upper molars (vestibular cusps) and lower molars (central fossae) showed normal values (Table 1).

Table 1. Upper and lower initial transverse measurements

\begin{tabular}{lc} 
Tooth & Measures $(\mathrm{mm})^{1}$ \\
\hline $14-24$ & 35 \\
$15-25$ & 40 \\
$16-36$ & 48 \\
$24-34$ & 34 \\
$25-35$ & 40 \\
$26-36$ & 49 \\
\hline
\end{tabular}

${ }^{1}$ Millimeters

The panoramic radiography shows 28 teeth. Adequate crown-root relationship and bone support. Teeth divergence: 11-21-13-23(Fig 4). 


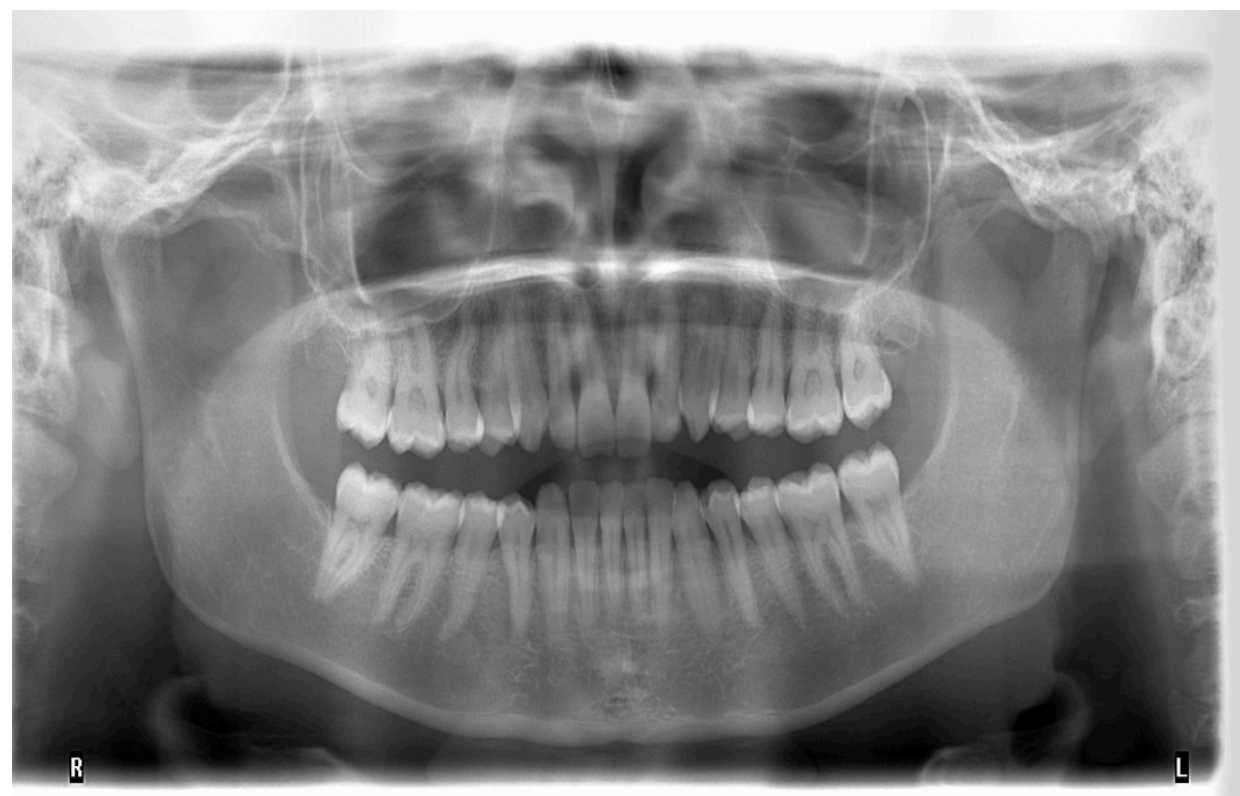

Figure 4. Initial panoramic radiograph

Cephalometric analysis (Fig 5) revealed a skeletal class II due to mandibular retrusion (Table 2), growth in the vertical direction. Also the analysis showed mesofacial biotype.
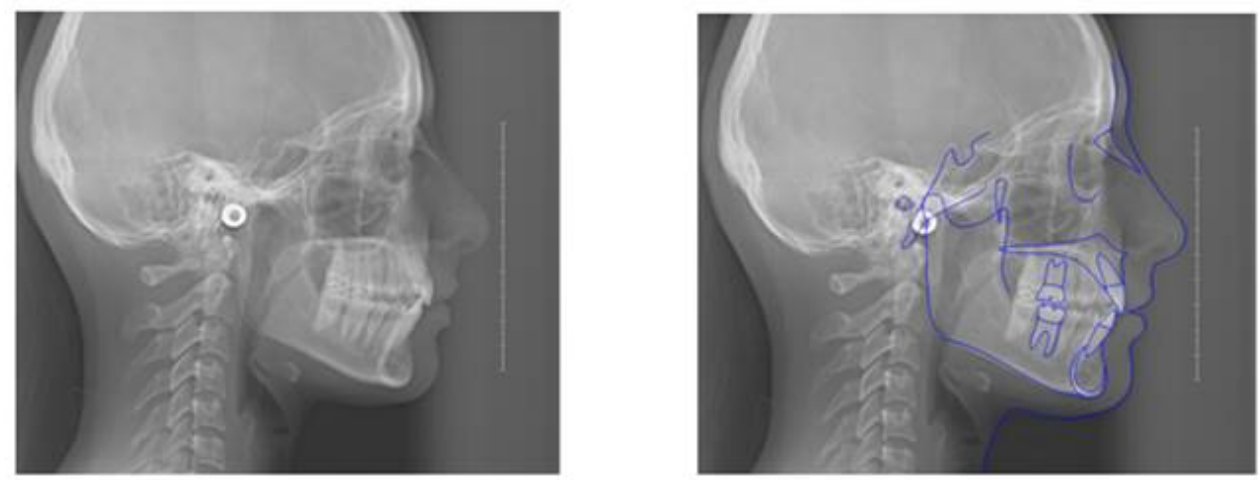

Figure 5. Initial cephalometric profile radiograph and cephalometric tracing

Table 2. Initial cephalometric measure

\begin{tabular}{lll}
\hline Plane & Norm & Initial \\
\hline SNA & $82^{\circ} \pm 2^{\circ}$ & $83^{\circ}$ \\
SNB & $80^{\circ} \pm 2^{\circ}$ & $77^{\circ}$ \\
ANB & $2^{\circ}$ & $5^{\circ}$ \\
Angle of convexity & $2 \pm 2 \mathrm{~mm}$ & $5.2 \mathrm{~mm}$ \\
Maxillarydepth & $90^{\circ} \pm 3^{\circ}$ & $96^{\circ}$ \\
Facial depth & $87^{\circ} \pm 3^{\circ}$ & $90^{\circ}$ \\
U1. UPP-PP & $110^{\circ} \pm 5^{\circ}$ & $112^{\circ}$ \\
U1. UPP-Pog & $3.5 \pm 2.3 \mathrm{~mm}$ & $2.5 \mathrm{~mm}$ \\
IMPA & $90^{\circ} \pm 5^{\circ}$ & $98^{\circ}$ \\
L1. Low-A Pog & $0.5 \mathrm{~mm}$ & -1 \\
\hline
\end{tabular}




\section{Treatment Planning}

In that way it was solved the crowding in both upper and lower arches and the severe rotation of 33 tooth $\left(46^{\circ}\right)$ using Invisalign system as well as the canine and molar relationship, dental verticalization, adequate over jet, overbite and dental midline using Invisalign system.

\section{Treatment Progress}

The treatment began with some dental impressions taking of the upper and lower arches using polyvinyl siloxane. The impressions were sent to Align Technology to fabricate the aligners. Align Technology designed a threedimensional image from the sent impressions and performed a "virtual treatment" using the ClinCheck 3.0. The instructions for the system were: derotations and verticalizations of upper and lower teeth, severe canine rotation an optimized attachment were requested, to solve the crowding anterior proinclination without interproximal reduction, also it was required to keep the molar relationship.

\section{ClinCheck and aligner}

Invislign treatment was planned to correct the dental crowding and the severe rotation of 33 tooth $\left(46^{\circ}\right)$. The final ClinCheck 3.0 provided 14 aligners for the upper and lower arches.

Each aligner was worn for 2 weeks (15 days). No inter-proximal reduction was indicated for the correction of the crowding. To improve the results, Invisalign introduced optimized attachments to achieve a greater predictable rotation movement for premolars and canines (Fig 6).

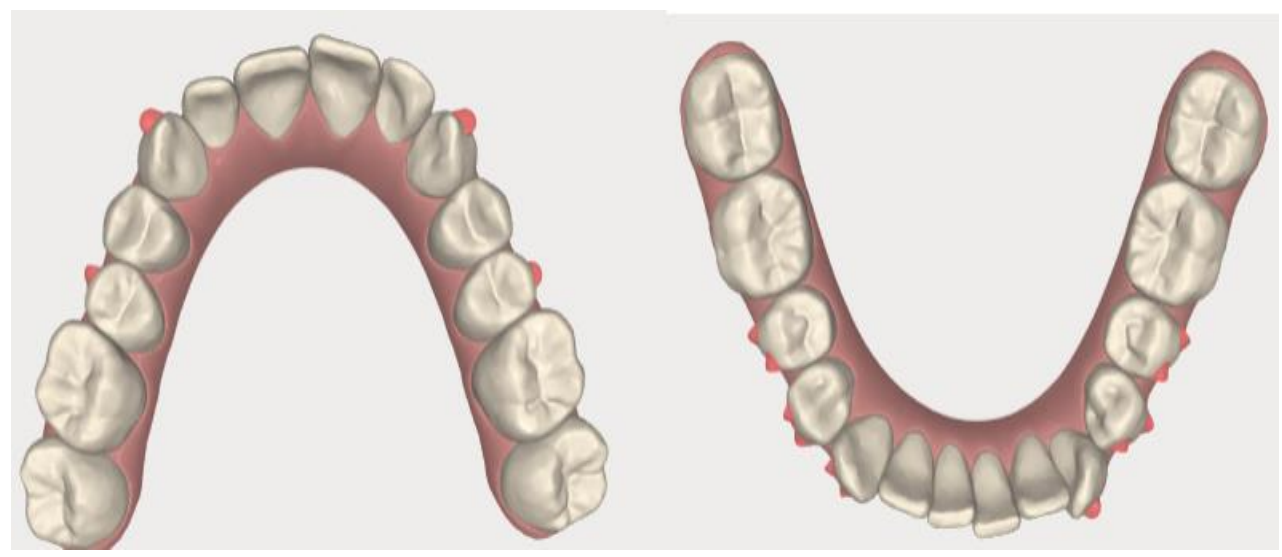

Figure 6.Attachmentes on upper and lower teeth. Severe canine lower rotation

Several attachments were bonded to the upper (13-15-23-25) and lower (33-4344-45-34-35) teeth in order to improve the retention and correct position within the dental arches. The duration of the treatment was approximately eight months. 


\section{Treatment results}

In Post-treatment extraoral photographs, no significant changes were observed at the end of the treatment (Fig7). Intraoral photographs showed an important and notable aesthetics improvement (Fig 8). The canine relationship improved slightly and molar Class I relationship was maintained (Fig 9). An increase in transverse diameter was observed at the first premolars level, second premolars and first molars (Table 3). The overbite improved (Table 4). The crowding and the severe canine rotation were corrected (Fig 10). No obvious root resorption was radiographically evident (Fig 11) and slight cephalometric changes (Fig 12) (Table 5).
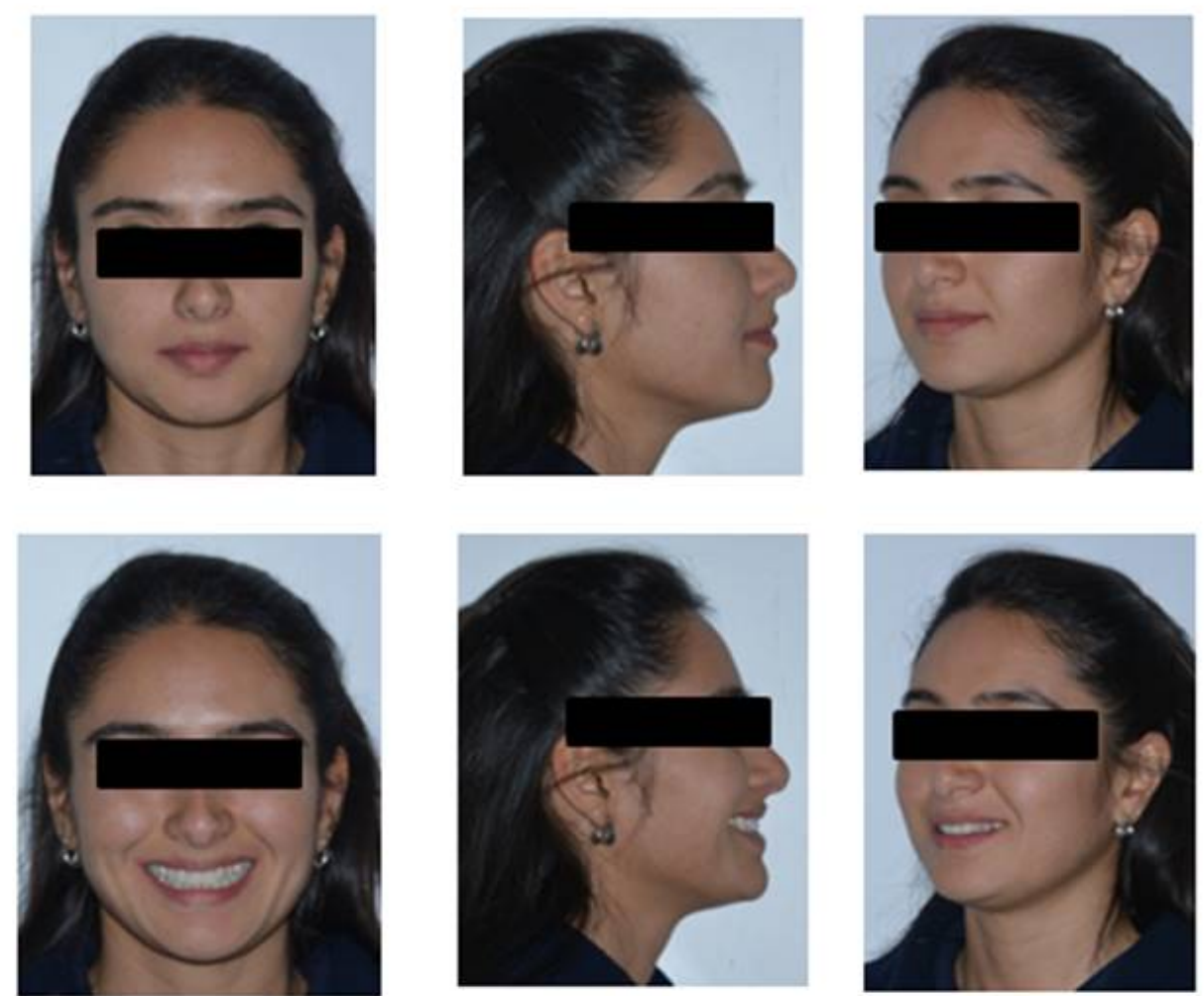

Figure 7. Extraoralphotographs at the end of treatment 

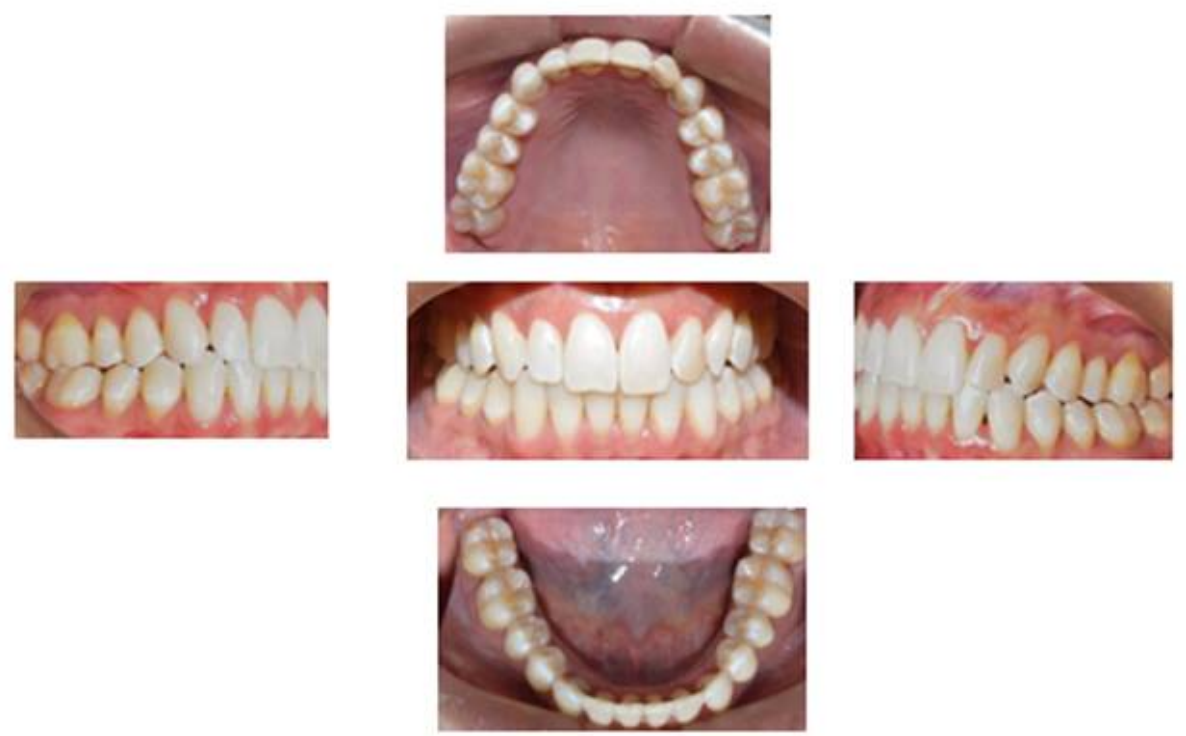

Figure 8. Intraoral Photographs at the end of treatment
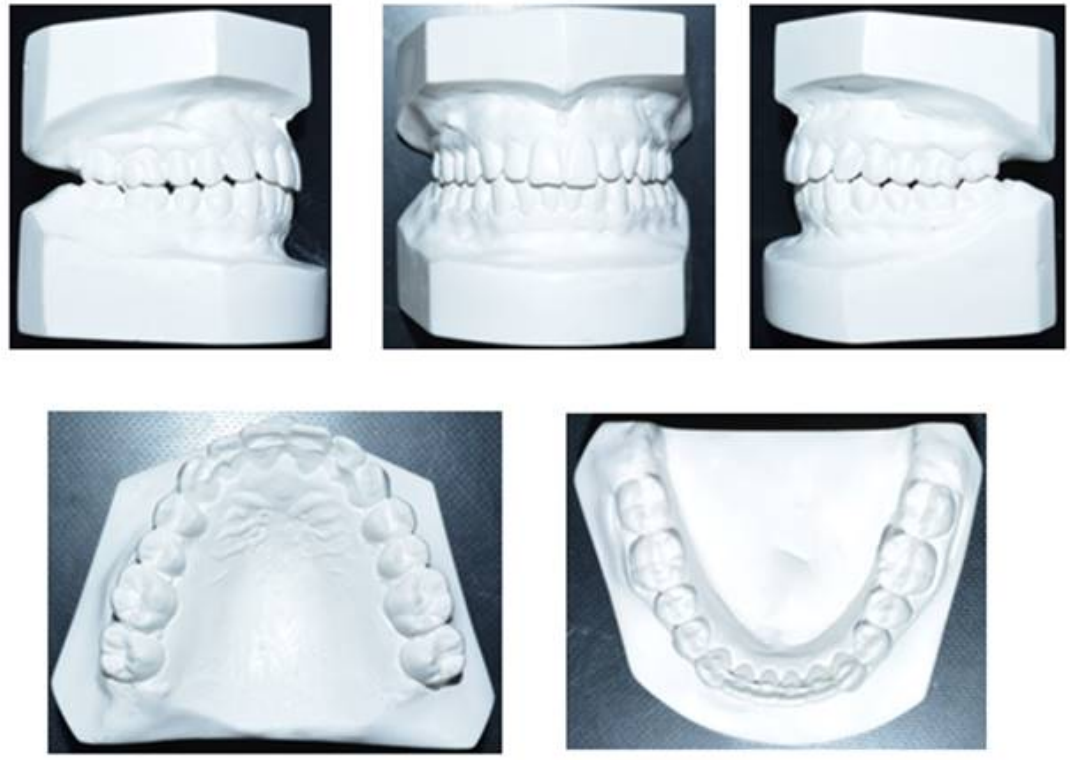

Figure 9.Final dental cast

Table 3. Initial and final transversal measures

\begin{tabular}{ccc}
\hline Teeth & $\begin{array}{c}\text { Initialmeasures } \\
(\mathbf{m m})\end{array}$ & $\begin{array}{c}\text { Final measures } \\
(\mathbf{m m})\end{array}$ \\
\hline $14-24$ & 35 & 37 \\
$15-25$ & 40 & 42 \\
$16-36$ & 48 & 50 \\
$24-34$ & 34 & 35 \\
$25-35$ & 40 & 41 \\
$26-36$ & 49 & 50 \\
\hline
\end{tabular}


Table 4. Initial and final Overjet-Overbite

\begin{tabular}{ccc}
\hline & Initial ( $\mathbf{m m})$ & Final $(\mathbf{m m})$ \\
\hline Overjet & 3.5 & 2.5 \\
Overbite & 3.5 & 3.5 \\
\hline
\end{tabular}

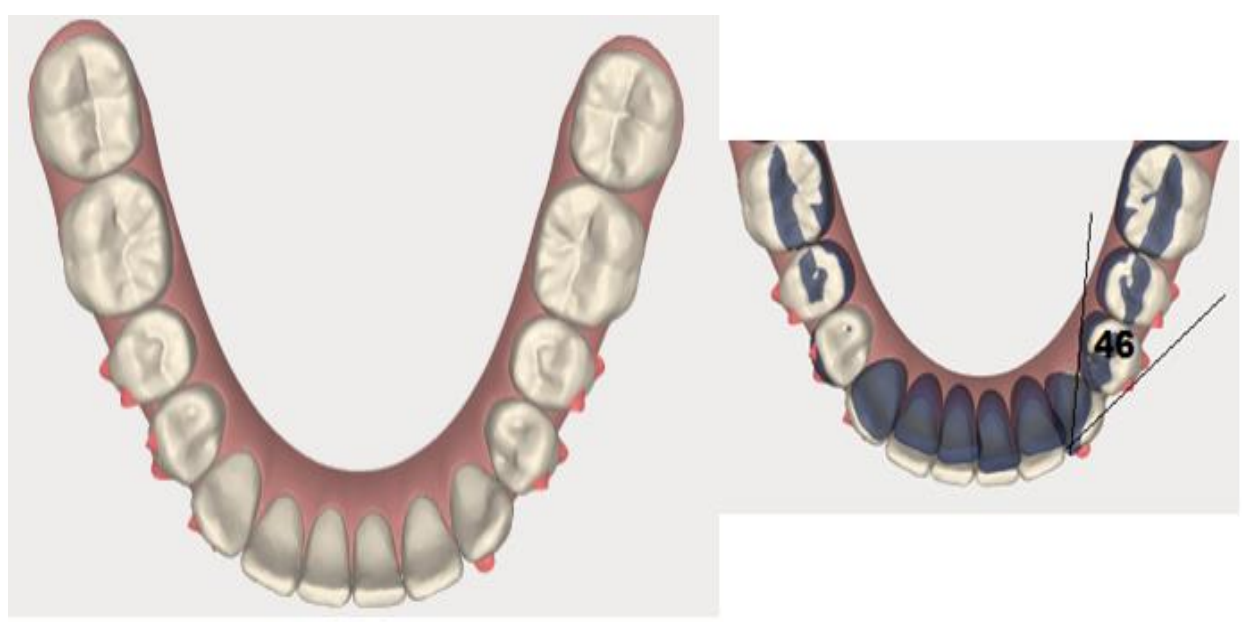

Figure 10. Superimposition of dental movement (Initial blue-final white) shows the degrees of rotational correction.

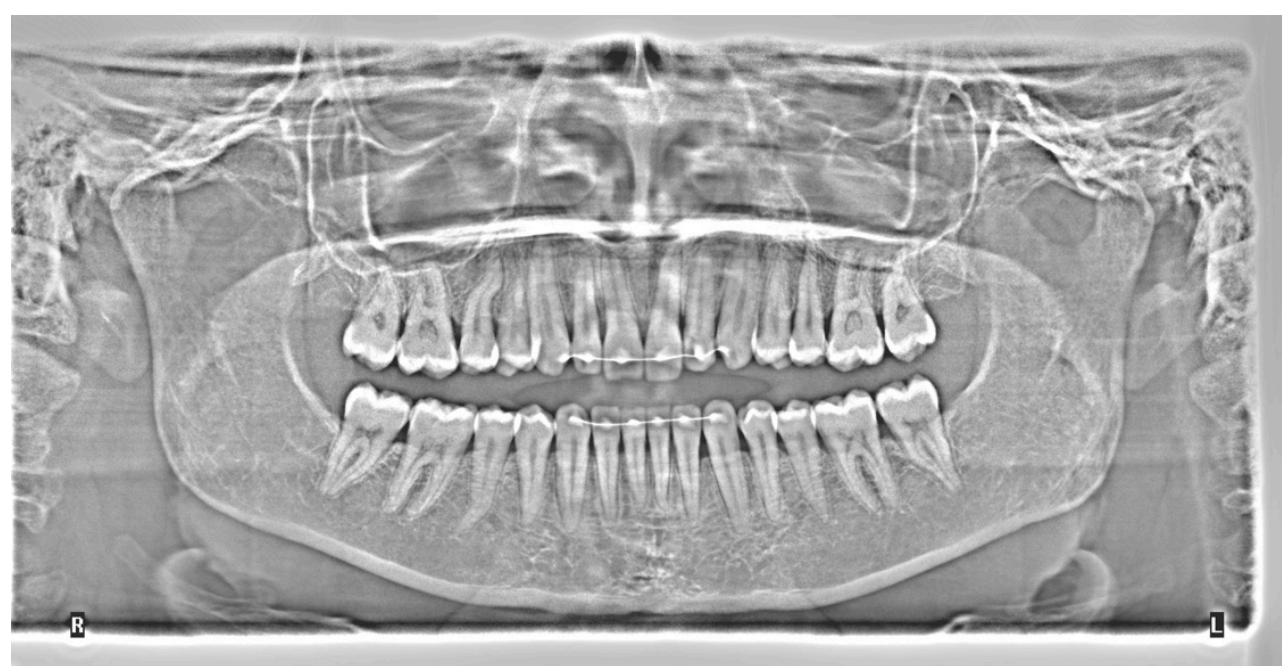

Figure 11. No obvious root resorption was radiographically evident at the end of treatment 

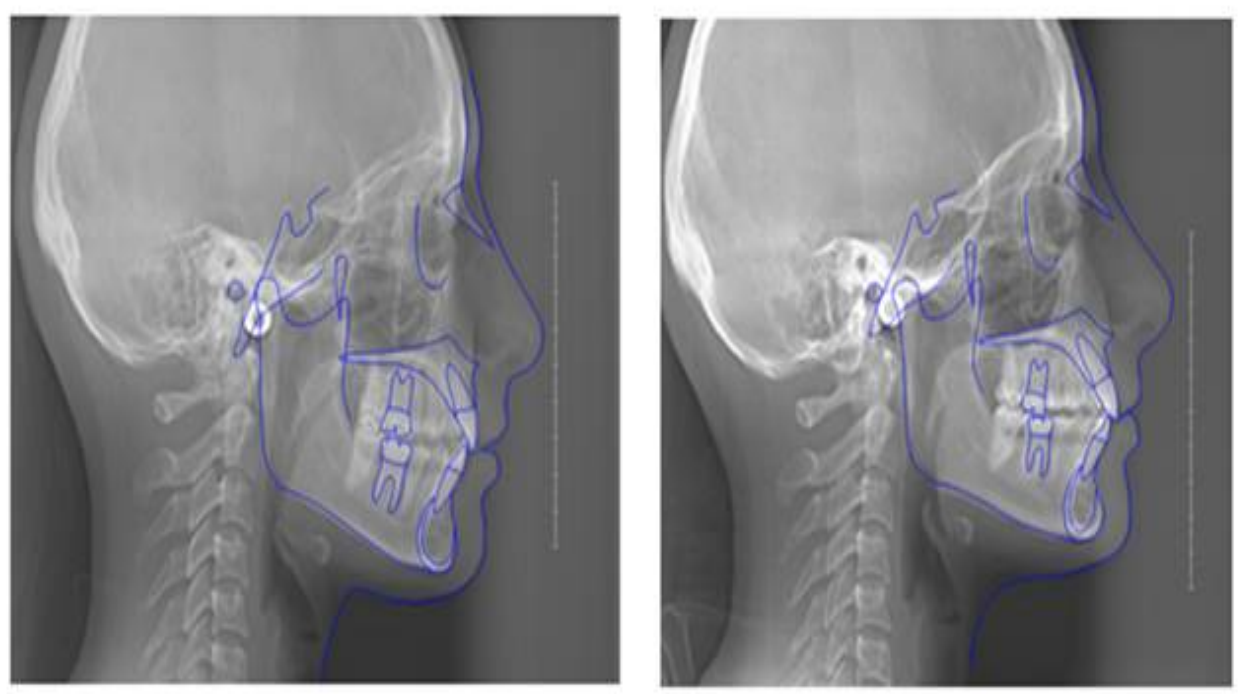

Figure 12.Initial cephalic radiography (left) and final (right)

Table 5.Initial and final cephalometric values

\begin{tabular}{llll}
\hline Plane & Norm & Initial & Final \\
\hline SNA & $82^{\circ} \pm 2^{\circ}$ & $83^{\circ}$ & $83^{\circ}$ \\
SNB & $80^{\circ} \pm 2^{\circ}$ & $77^{\circ}$ & $77^{\circ}$ \\
ANB & $2^{\circ}$ & $5^{\circ}$ & $5^{\circ}$ \\
CONVEXITY & $2 \pm 2 \mathrm{~mm}$ & $5.2 \mathrm{~mm}$ & $5.1^{\circ}$ \\
Maxillarydepth & $90^{\circ} \pm 3^{\circ}$ & $96^{\circ}$ & $96^{\circ}$ \\
Facial depth & $87^{\circ} \pm 3^{\circ}$ & $90^{\circ}$ & $91^{\circ}$ \\
U1. Upp-PP & $110^{\circ} \pm 5^{\circ}$ & $112^{\circ}$ & $115^{\circ}$ \\
U1.Upp-APog & $3.5 \pm 2.3 \mathrm{~mm}$ & $2.5 \mathrm{~mm}$ & $4.5 \mathrm{~mm}$ \\
IMPA & $90^{\circ} \pm 5^{\circ}$ & $98^{\circ}$ & $111^{\circ}$ \\
L1.Low-A Pog & $1 \mathrm{~mm}$ & $-0.5 \mathrm{~mm}$ & $1.5 \mathrm{~mm}$ \\
\hline
\end{tabular}

After the treatment was completed and the upper and lower fixed contention was placed to the patient, the final outcomes were registered. It is important to note that the patient strictly used all the aligners and attended the appointments scheduled by the clinician.

\section{Discussion}

In the following case report the severe canine rotation of 33 tooth (46 degrees) and upper and lower crowding arches was satisfactorily resolved using the Invisalign system.

Despite inter proximal enamel reduction was not carried out the desrotation was achieved with optimized attachments (Invisalign system).

Previous studies have reported that significant rotations of teeth particularly in the mandibular canines have not been achieved satisfactorily using the Invisalign system. [12] In this regard Gianluigi and Tommaso who carried out a treatment with Invisalign found that the rotation of mandibular canines only was 
achieved one third of the expected and the accuracy of canine rotation (more than 20 degrees) [10] was significantly lower than the rotation of the other teeth $[9,13]$.

However, the use of Invisalign system allowed that our patient resolved the desrotation of all her teeth including a high rotation of the mandibular canine. In this context, Align Technology Inc. recommends auxiliaries to help rotational movement and avoid "uncorrected rotations" resulting in the need for refinement impressions or conversion to fixed appliances [14].

The upper and lower crowding of arches was resolved effectively. One of the possible explanations is positional dental changes. This fact support the findings found in other investigations where the lower anterior crowding was resolved through of protrusion of the anterior teeth (enlargement of the anterior arch length)[15] increasing the mandibular intercanine distance (lower arch) [16]. In relation to the stability of the treatment regarding to dental alignment and rotations, a study carried out by Kuncio et al. indicated that the patients treated with Invisalign showed more deterioration in the alignment of the dentition than the patients treated with traditional fixed appliances. This is clinically important because tooth alignment is probably the main reason why people prefer orthodontic treatment [17].

\section{Conclusions}

The mentioned case report about the derotation of rounded teeth was completed and the attachments optimized for the derotation in order to get good results.

The treatment with the Invisalign system resolved the complaint of our patients so this system could be considered as an option that offered good outcomes in the treatment of upper and lower crowding of arches involving severe canine rotation.

\section{Acknowledgements}

We thank to Dr. Ebingen Villavicencio by his support in the critical review of our manuscript.

\section{References:}

1. Shalish M, Cooper-Kazaz R, Ivgi I, Canetti L, Tsur B, Bachar E, et al. Adult patients' adjustability to orthodontic appliances. Part I: a comparison between Labial, Lingual, and Invisalign $^{T M}$. European Journal of Orthodontics. 2012;34(6):724-30.

2. Pagani R, Signorino F, Poli PP, Manzini P, Panisi I. The Use of Invisalign $($ System in the Management of the Orthodontic Treatment before and after Class III Surgical Approach. Case Rep Dent. 2016;2016:9231219. doi: 10.1155/2016/9231219. Epub 2016 Jun 27.

3. Fujiyama, K., Honjo, T., Suzuki, M., Matsuoka, S., \& Deguchi, T. (). Analysis of pain level in cases treated with Invisalign aligner: comparison with fixed edgewise appliance therapy. Progress in Orthodontics,2014 15(1), 64. 
4. Zawawi KH. Orthodontic Treatment of a Mandibular Incisor Extraction Case with Invisalign. Case Reports in Dentistry. 2014;2014:4.

5. Ogura Y, Yanagisawa W, Sugiura M, Fujita Y, Yamaguchi T, Maki K. Treatment of a Patient with Class I Malocclusion and Severe Tooth Crowding Using Invisalign and Fixed Appliances. Dental Medicine Research. 2014;34(1):36-40.

6. Robert L. Boyd, D. "Esthetic Orthodontic Treatment Using the Invisalign Appliance for Moderate to Complex Malocclusions" Journal of Dental Education August 1, 2008 vol. 72 no. 8 948-967. .

7. Duncan LO, Piedade L, Lekic M, Cunha RS, Wiltshire WA. Changes in mandibular incisor position and arch form resulting from Invisalign correction of the crowded dentition treated nonextraction. The Angle Orthodontist. 2016;86(4):577-83.

8. Grünheid T, Loh C, Larson BE. How accurate is Invisalign in nonextraction cases? Are predicted tooth positions achieved? The Angle Orthodontist. 2017;87(6):809-15.

9. Kravitz ND, Kusnoto B, BeGole E, Obrez A, Agran B. How well does Invisalign work? A prospective clinical study evaluating the efficacy of tooth movement with Invisalign. American Journal of Orthodontics and Dentofacial Orthopedics. 2009;135(1):27-35.

10. Gianluigi F, Tommaso C. Correction of severe tooth rotations using clear aligners: A case report . Australian Orthodontic Journal, 2012;28: 245-249.

11. Kravitz ND, Kusnoto B, BeGole E, Obrez A, Agran B. How well does Invisalign work? A prospective clinical study evaluating the efficacy of tooth movement with Invisalign. Am J Orthod Dentofac Orthop. 2009;135.

12. Phan X, Ling P.Clinical Limitations of Invisalign. Journal of Canadian Dental Association, 2007;73:263-266.

13. Wiboonsirikul S, Manopatanakul S, Dechkunakorn S. Invisalign update: A review of articles. Dental Journal, 2014;34:174-180.

14. Kravitz ND, Kusnoto B, Agran B, Viana G. Influence of Attachments and Interproximal Reduction on the Accuracy of Canine Rotation with Invisalign. The Angle Orthodontist. $2008 ; 78(4): 682-7$.

15. Krieger E, Seiferth J, Marinello I, Jung BA, Wriedt S, Jacobs C, et al. Invisalign $(\mathbb{R}$ treatment in the anterior region. Journal of Orofacial Orthopedics / Fortschritte der Kieferorthopädie. 2012;73(5):365-76.

16. Grünheid T, Gaalaas S, Hamdan H, Larson BE. Effect of clear aligner therapy on the buccolingual inclination of mandibular canines and the intercanine distance. The Angle Orthodontist. 2016;86(1):10-6.

17. Kuncio D, Maganzini A, Shelton C, Freeman K. Invisalign and Traditional Orthodontic Treatment Postretention Outcomes Compared Using the American Board of Orthodontics Objective Grading System. The Angle Orthodontist. 2007;77(5):864-9. 